\title{
Research on Advertisement Translation from the Dual Perspective of Teleology \& Reception Aesthetics
}

\author{
Changhong Zhai \\ School of Foreign Languages \\ Wuhan Polytechnic University \\ Wuhan, China \\ 594561792@qq.com
}

\begin{abstract}
A successful advertisement translation requires the translator to deal with what the advertisements focus on and try to reduce the cultural discrepancy. Moreover, the translators are demanded that they not only focus on the original text, but also pay attention to the cultural significance of the original content and the connotative meaning of the advertisement, which enables readers to accept it easier and more importantly achieves the purpose of promotion. In this paper, advertisement translation will be illustrated from the dual perspective of teleology \& reception aesthetics, and will mainly focus on the strategies and methods.
\end{abstract}

Keywords-advertisement; teleology; reception aesthetic

\section{INTRODUCTION}

Advertising plays an important role in the commercial world. Advertisement translation is a major means for the commodity to enter the international market. There are many researches of advertisement translation at home and abroad. However, research on advertisement translation from the dual perspective of teleology \& reception aesthetics is a new research field. Advertisement translation should be centered on readers under the principle of teleology, considering the audiences' vision and aesthetic taste, thus awaken the reader's imagination and motivate their action to achieve this desire. Advertising translation has gone a long way, but most studies only focus on the simple language features, rhetorical devices and some ostensible characteristics. Traditional translation has been unable to adapt to customer's requirements.

\section{The Motivation to StUdy AdVERTiSEMENT TRANSLATION}

Translation activity means not only the process of translation, but also the results of it. H.G.Widdowson pointed out that the difference between "result" and "process" is of great importance, which can make us aware of the deviation and defect of translation research, at the same time provide us a possibility of acknowledging the essence of translation from an overall aspect. However, most translation focuses on the result of the bilingual conversion instead of its process. This phenomenon can't reveal the essence of translation, which makes scholars realize the imperfection of translation research. Bilingual conversion is a complex cognitive psychological process. It includes direct language process, and also the deeper psychological process. With the economic development, Chinese products enter the international market, so are foreign products. Competition exists every corner in the world. In modern society, as the embodiment of commerce, advertisement is becoming an important part of our daily life. Not only is it supposed to be appealing, it is also used as a tool for manufacturers to improve their products' marketability. With globalization accelerating, more and more businesses of all types are operating internationally in various ways. A famous American marketing association once defined advertisement like this: advertisement is the non-personal communication of information usually paid for and usually persuasive in nature about products, services or idea by identified sponsors through the various media.

\section{THE OVERVIEW OF THE MAIN VIEWPOINTS OF RECEPTION AESTHETICS}

\section{A. Review of the Development of Reception Aesthetics}

Reception Aesthetics theory put forward by H.R.Jauss and Wolfganglser opened up a new revolution in advertisement translation. The market competition of various products is becoming increasingly fierce, and advertisement is now ranking among the world's ten largest advertising powers. So far, many domestic and foreign researchers have carried out a lot of translation practice and theoretical research on the issue of reception aesthetics. However, this kind of research began very late in China, compared to that in foreign countries, as a result, we fall behind other countries in the development level and research result. What's more, we are also behind other countries in the process of introducing this theory. Because of lack of systematicness, it also brings different levels of problems and misunderstandings. Reception aesthetics theory shakes the traditional translation view, it will inevitably face large barrier when introducing this theory to the translation circles.[1]

Reception aesthetics, also called reception theory, was originated from federal Germany in the 1960 s, it was founded by several teenage scholars in Constance University, such as H.R.Jauss and Wolfgang Iser. This informal academic group was later called "Constance School". As one of the main representative of this school, H.R.Jauss insisted that in the triangle of writers, readers and works, readers are not passive, instead, they are "the composition of the dynamic history" and the realization of meaning depends on the reader's expectations, translators should target on not only the readers' emotional need, which can help achieve their psychological identification, 
but also on the readers' cultural and psychological aspects, thus avoid the conflict of understanding. There are mainly two schools of reception aesthetics study: one is "reception research", the other is "effect research". The former, represented by Jauss, emphasizes the readers' horizon of expectations and aesthetic experience. According to him, the horizon of expectations refers to the partial and moving perspective of human experience and knowledge. [2]There is pre-understanding or pre-knowledge structure in the readers' mind, before he sets out to read a new literary work. In translating, the differentiation in the horizon of expectations between the original text and the translator and the consideration for the readers' horizon of expectations definitely results in the diversity of translations. The latter represented by Iser, stresses the text research during the reception process. It mainly studies the interaction between the text and the reader and believes that reading is a communication between the two. Iser claims that any work has two sides. The artistic side contains indeterminacies to be settled by the reader; the aesthetic side, the readers' realization, means each individual reader's understanding of the works on the basis of his own knowledge and experiences. Each translator with his own particular properties comes to the different concentration in the aesthetic side for those indeterminacies in the artistic side, hence the different interpretation of the original text. The theory of reception aesthetic transfers the attention from the content to the readers' acceptance. It decides that whether the readers' acceptance can be realized, in which way and what appearance it is achieved, as well as the degree of realization and the effect. The key to producing meaning is by "horizon blending", that is, the mutual blending and effect of receiver's horizon of expectations and life experience.

\section{B. The enlightenment of reception aesthetics on advertisement translation}

The rise of reception aesthetics has made it possible for people to view advertisement translation from a new perspective. In the theory of Eugene Eoyang, a professor from Indiana University, reception aesthetics plays a very important part. Assuming that a perfect understanding and translation of the original text is impossible, Eugene Eoyang believed that one translated version is only the result of a particular, personal interpretation of the original work by a certain translator. The translated version is not only an interpretation of the original text, but also a text to be interpreted by its target readers. This means that the translator should take into consideration both the original text and the target readers during the translation process. [3]Reception aesthetics was applied in translation research field in western countries in the late 1970s. Since Steyn specifically described the translation mode, reception aesthetics has become one of the important aspects in the contemporary translation studies. In the late 1980s, reception aesthetics entered Chinese translation field. The first relevant paper is "Circulating of Interpretation, Acceptance and again Recreation" written by Yang Wuneng in 1987. The article pointed out that, literature translator is both an interpreter and a receiver. The whole process of translation activities includes the translator $\rightarrow$ the author and the reader $\rightarrow$ author's interpretation, acceptance and again recreation. Later, the translation field in China published other related papers in succession, from different angles, different ways, and different levels to probe into this subject.

According to reception aesthetics, any reader will consciously or unconsciously produce specific horizon of expectations before their reading activities. Reception aesthetics is centered on readers, tries to meet readers' expectation horizon and aesthetic taste, and requires the writers to endow enough "uncertainty" and "blank" to their works, calls for the readers potential imagination, and in the end achieves the anticipated effect. In the enlightenment of reception aesthetics, the aim of advertisement translation should be to awaken the readers' memory, put them in the specific experience in order to arouse their expectations and then stimulate or change those expectations in their purchase action.

One of the most important contributions reception aesthetics offers is that it identifies the readers' central position. Any advertisement is created for readers. The realization of advertisement effect mainly depends on whether or not the readers can accept the promoting. In order to achieve this purpose, the translators must take readers into consideration, grasp their subjective initiative, and blend with the readers in the horizon. Reception aesthetics gives full consideration to the readers, which enlightens advertisement translation studies a lot and allows us a better understanding of different advertisement translations. "Horizon of expectations" refers to the stereotype formed by reading experience after readers' reading so many literal works. Horizon of expectations requires translators to take the demands of "potential readers" into consideration in translating unconsciously. Readers' horizon of expectations is represented as readers' readiness to accept. Successful advertisement translation should make consumers find the similarities between advertisement and their horizon of expectations, or higher than the horizon of expectations, and eventually accept the advertisement.

For example, the advertisement of Nike is "just do it", it embodies that the businessmen respect the individual consumers, it fits for the audiences' (sports community) expectation, that is, highlighting the character and the individual, so it is easy for readers to accept. A pawn slogan "Shang dang buchikui", if we translate word by word, the translation will arouse readers of previous experience that they think pawn is humiliating. If it is translated as "Go to the Pawn, you won't be Down", it will effectively avoid the readers' conflicted emotion.

Reception aesthetics provides a new theoretical perspective and research methods of advertisement translation. The translator must center on readers, reveal the information and value of advertisement, take full consideration of the consumers' horizon of expectations and aesthetic experience, bring it into certain atmosphere, and arouse their imagination and desire for the products. This requires translators to have enough aesthetic qualities and language culture. Apart from catering to readers tastes, at the same time, the translators should also construct the text that is higher than readers' horizon, improve the tastes of the public, attract consumers and promote the cultural progress. 


\section{THE OVERVIEW OF THE MAIN VIEWPOINTS OF TELEOLOGY THEORY}

\section{A. Review of the Development of Teleology Theory}

Teleology theory was first put forward by Vermeer in the 1970 s, it is a leading theory in the functional translation theory. Translation is also a way of communication, so the aim of translating plays a decisive role in the entire translation behavior. Teleology theory is the most important theory in the functional school of translation studies. A translator should always choose translation methods purposefully. It holds that translation methods or strategies should be determined by the intended function of the target text and points out that certain translation methods which do not seem to conform to conventional translation criteria should be reappraised so that the purpose and function of the target text will be given due attention in the translation process. This is in accordance with the theory that any action involves an intention. Translation strategy must be determined according to the translation purpose. Advertisement translation belongs to the application territory, which in particular emphasizes on the transmission of information, its contents and effect. Advertisement translation aims to achieve the expecting purpose, the ultimate goal is to influence consumers' psychological level, and induce consumers to purchase the promoting products. The teleology theory provides a theoretical basis for the advertisement translation research and it is rational and smooth by using teleology theory to translate advertisement.

\section{B. The Enlightenment of Teleology Theory on Advertisement Translation}

The main function of advertisement is to convey products information to consumers, so the primary purpose of advertisement translation is to cross cultural barriers, and realize the promotional function of source language in the target language culture. Advertisement texts try to realize the effective spreading of advertisement information with its essence of persuasion. The informational function and persuasive function are the main function of advertisement; its stylistic function decides the special style of advertisement language. Its features can be concluded as short, persuasive, and easy to understand. The real purpose of advertising is not only to provide information, but also to realize its persuasive function and eventually cause consumer to purchase. Therefore, the nature of the advertisement translation is to achieve the expecting purpose and function, target on the readers, orient on the target language and culture. The translator should adopt flexible translation strategies, reproduce the advertisement's persuasive function in the environment of target language culture, and realize the cross-cultural communication.[4]

In the teleology, translation is defined as "a complex action designed to achieve a particular purpose", which takes place in a given situation and modifies the situation. Since advertisement translation is a cross-cultural action of communication, it is necessary to find a cut-in between teleology and advertisement translation. According to the teleology theory, translation should follow the three principals: purpose, coherence and faithfulness; among the three principals, purpose is the supreme principal and coherence and faithfulness are included in the purpose principal. In the purpose principal, any translation activity involves a certain objective, and it is this objective that decides the whole translation. In the coherence rule, the translation must comply with the standard that it is coherent in the contents, that is to say, the translation must be understood and received in the target language culture and make sense in the communicational environment. In the faithfulness principal, the translation should be in accordance with the original contents. Only when the advertisement translation takes on the equivalent influence and expression to the original content can the translation be called a successful one. For example, when translating "He yibei ningmeng lingni yishenxingnao", we may just translate it as: "A Glass of Instant Lemon Tea Makes You Refreshed." It is a declarative sentence, which can't reach the expected effect. If we try to use a question or exclamatory sentence, the effect will be quite different, such as: "For Refreshment? A Glass of Instant Lemon Tea!" Furthermore, by using teleology theory, some brand has achieved great success in the translation. To take another example, "Shu fujia" is translated as "Safeguard". This translation is equivalent not only in form but also in function and highlights the prominent sterilizing effect of this soap.

Nord pointed out that, in the process of translating, what the translators should do is to translate meaningful texts for the target readers, the direct and purposeful character again shows that there should be a value, belief and shifting of customs in translating, trying to make the translation in target language adapt to consumers' acceptance.

First of all, the translator should analyze the hidden information in the viewpoint of readers. Due to the different languages and different cultural background, some communicative information is indicated in the source language, however, because of the readers' different recognition, it can't be recognized, for the readers, they will face confusion in understanding. As a result, it is required for the translators to make up for the lack of target language culture.[5]

Secondly, the author should adjust the source language information, and realize the best relevance between source language and target language. To provide the best relevance and avoid readers making unnecessary effort, in the process of choosing essential parts within the original text, it is wise to express the main information relevant to the communicative purpose of the original content, so additions and deletions of the original text is imperative.

In the process of translating, translators should change our concepts, prepare for the many aspects, care for the readers, think over the culture, and handle flexibly.

To begin with, the translators should pay attention to the change of concept and translation orientation. The teleology theory makes us pay full attention to purposes of different translation. The purpose of the advertisement is very clear--promoting goods, persuading customers and stimulating consumption. Accordingly, the advertisement translation should achieve this purpose in different languages. Reception aesthetics inspires us to treat our readers as the center, to grasp readers' initiative, blend the translators and readers in the horizon. The effect of advertising mainly depends on whether or not the readers can accept the propaganda. The process of 
translation should view readers as the main body, give full play to the receivers' aesthetic experience, thus make the translation vivid and readers piercing.

Then, translators should make careful preparation before translation. There are mainly four steps for the translators to prepare:

(a) To query the businessman of the detailed features of products, from the quality, place of origin, property, price, technological level and so on.

(b) To know about the specific purpose, medium of communication, and the target groups. Whether continuing to expand the market, printing on the magazine or on TV, and countries, age group, type of work of the target crowds are the factors to be considered.

(c) To lock the target crowds, understand the cultural convention and consumers' psychology, and learn about the taboos of translation. Any country or nation has many taboos, as to those ethnic customs having formed for thousands of years, we should give them necessary respect, and otherwise, it will impact the effect of translation.

(d) To care for the readers in translation. The attention of the target language readers first lies in taking consideration of the cultural discrepancies and cultural taboos. Let's take some brand name translation for example, if "Wuyang" bicycle is translated as "Five Rams bicycles" and Chinese "Fangfang" lipstick is translated as "Fangfang", although these trademarks can bring good associations in Chinese culture, they are contrary to English culture, because "ram" has some collisional meaning, and "fang" means the pointed teeth of poisonous snake. Just think who want to purchase a bicycle that is easy to collide and the lipstick that is poisonous?

Except for the language taboos caused by customs, translators should also notice some political, economic and cultural words with special cultural meaning. For example, in Chinese advertisement, we can often hear "Jin sanjiao". If "Jin Sanjiao" is translated as "Golden Triangle", it will cause conflicted emotion of readers, because "Golden Triangle" refers to places in southeast Asia that manufacture and sell drugs.

For the cultural information that does not cause cultural conflict, when translating, what translators should consider is whether the audience can understand, and whether it is necessary to translate this information. Let's look at the following advertisement. As for "He kongfu Jia Jiu, Zuo tianxia wenzhang", there are two translation texts: Translation 1: Kongfu down, Cases done; translation 2: Confucian Spirit triggers provokes your mind.

As the founder of Confucianism, Confucius is respected by the later generations. Confucius is also well-known by western people, but as for "Kongfu", this word can only make westerners associate with Chinese martial (Chinese kung fu), the original text is the "culture", but "kung fu" is "force", which is far from Confucius. Therefore, considering the cognitive level and acceptability of the target crowds, the second translation is more suitable for the cultural psychology of western consumers, furthermore, Confucian Spirit and British Spirit are slightly different in advertisement expression, and they are easy to arouse western consumers' association.

Mutual international understanding is unbalanced and always changing. When the audience change their understanding and acceptability of foreign cultures, translating process relevant to cultural factors will also change, to ensure the coherence and smooth transmission of the advertisement information, and at the same time cater to the aesthetic appealing, and finally reach the purpose of promoting.

\section{CONCLUSION}

The paper attempts to apply reception aesthetics and the teleology theory to the study of advertisement translation. These two theories have internal unity, which provides practical effect for advertisement translation. In the translation of advertisement, we must always keep our goals in mind, pay full attention to the cultural difference between source language and target language, and take reader's ability of reception and horizon of expectations into consideration, which will help improve our level of advertisement translation.

\section{REFERENCES}

[1] Venuti, Lawrence. The Translator's Invisibility [M]. London \& New York: Routledge, 1995.

[2] Munday, Jeremy. Introducing Translation Studies: Theories and Application [M]. London and New York: Routledge, 2001.

[3] Gentzler, Edwin. Contemporary Translation Theories [M]. Shanghai: Shanghai Foreign Language Education Press, 2004.

[4] Lefevere, Andre. Translation, History, Culture [M]. London\& New York: Routledge, 1992.

[5] McArthur, T. (ed.) Longman Lexicon of Contemporary English [Z]. Longman Group Ltd. 1981. 